\section{LA IDENTIDAD LINGÜÍSTICA ARGENTINA A TRAVÉS DE BORGES Y PUIG}

\section{Sonia Thon}

Acadia University

\section{THE ARGENTINIAN LINGUISTIC IDENTITY THROUGH BORGES AND PUIG}

\begin{abstract}
The identity of the Argentinian linguistic expression has been studied in depth by many literary critics and linguists who demonstrated the close relationship that exists between language, ideology, and socio-historic context; especially, when incorporating the concept of oral and colloquial language to the narrative discourse. We are basing this paper on the studies of authors such as: Beatriz Sarlo, Walter Bruno Berg, Wolf Oesterreicher, Maria Zulema Kulikowsi, and others in order to situate two Argentinian writers, Jorge Luis Borges and Manuel Puig, within their historic period in order to reveal how their personal and social anxieties impacted the perception of their work as representative of the Argentinian language.
\end{abstract}

KEY WORDS: Borges; Puig; Argentina; literature; linguistics; sociolinguistics; dialects; discourse; immigration; tango; lunfardo.

El conflicto lingüistico entorno a la identidad de la expresión argentina ha sido estudiado a fondo por numerosos críticos literarios y lingüistas ${ }^{1}$ que demostraron la estrecha relación que existe entre lengua, ideología y contexto socio-histórico. A estas investigaciones se han sumado las que se ocuparon de la oralidad en el texto escrito ${ }^{2}$ explicando que el discurso narrativo no sólo abarca las reglas y normas de la lengua, sino también la realización de modelos y tradiciones discursivas que aluden a la interacción verbal cotidiana ${ }^{3}$. La incorporación de la "coloquialidad" a la totalidad del discurso (con su carga de marcas, registros y dialectos) recrea, según María Zulema Kulikowski:

el universo de lo privado, de lo que puede decirse a medias sin el temor de no ser comprendido... [transformando] lo cotidiano en el gran tema, hace de lo aparentemente banal una materialidad que cobra matices de status literarios. Junto al lenguaje "autorizado" por el canon literario va creándose un lenguaje paralelo, un "eco" familiar que se interpreta a partir de la experiencia del habla del lector. Los personajes "se hablan", se describen a sí mismos, se cuentan, acortan las distancias porque hablan desde sus experiencias narrativas, lo que permite que reconstruyan lenguajes interiores, formas
RESUMEN: La identidad de la expresión lingüistica argentina ha sido estudiada a fondo por numerosos críticos literarios y lingüistas que demostraron la estrecha relación que existe entre lengua, ideología y contexto socio-histórico, especialmente al incorporarse al discurso narrativo el concepto de oralidad y "coloquialidad". En este ensayo nos basaremos en estudios de autores tales como Beatriz Sarlo, Walter Bruno Berg, Wolf Oesterreicher, María Zulema Kulikowski, entre otros, para situar a dos escritores argentinos, Jorge Luis Borges y Manuel Puig, dentro de su época y revelar cómo sus ansiedades personales y sociales impactaron la percepción de su obra como representativa de lo que se considera el lenguaje argentino.

PALABRAS CLAVE: Borges; Puig; Argentina; lingüística; dialectos: sociolingüística; discurso; inmigración; tango; lunfardo.

de decir por las que se filtran las voces sociales y las del propio narrador ${ }^{4}$.

Basándonos en esos estudios situaremos a dos escritores argentinos, Jorge Luis Borges y Manuel Puig, dentro de su época para revelar cómo sus ansiedades personales y sociales los Ilevaron a depender de una fantasía (Borges) o de una realidad distante (Puig) para afirmar su identidad lingüística y trascender más allá de sus límites geográficos.

El debate lingüístico que se inició después de la Independencia de España tuvo como campo de batalla la ciudad de Buenos Aires. Por un lado, se trataba de encontrar una forma de expresión propia que diferenciara y separara la nueva nación de su pasado colonial; por el otro, el único pasado -salvo el escaso aporte lingüístico indígena, mayormente semántico, y la locución criolla en la cual ya se notaba una cierta tonalidad y peculiaridad idiosincráticaestaba dado por el idioma heredado de España. Aunque las personalidades activamente involucradas en el debate no desconocían la dinámica evolutiva de la lengua, aceptaban determinadas variaciones léxicas a la vez que rechazaban otros niveles de lengua, sobre todo el morfosintáctico. En 1889 Alberto del Solar escribe: 
Nuestra doctrina, se reduce, pues a sostener que en las familias de las lenguas, hay giros, y voces que deben aceptarse por legítimas, como hay otras que deben rechazarse por bastardas. So pretexto de aumentar la especie, no hemos de tolerar que se autorice el libertinaje $\mathrm{e}^{5}$.

El "español", que luego pasó a llamarse "castellano" y más adelante, debido a la presión nacionalista del momento, "idioma nacional" unido, en ciertos casos al concepto de "raza hispana", preocupaba seriamente a la elite argentina que temía el aumento del interés literario en el criollismo:

\begin{abstract}
"[término] acuñado a principios de siglo para designar un tipo de literatura, y luego el movimiento cultural, que pretendía ser la expresión de los nuevos grupos surgidos a partir de la asimilación de los inmigrantes a la sociedad y cultura argentinas. El criollismo significa asimismo -como en las restantes corrientes culturales del periodo- un intento de lograr la tan ansiada identidad nacional y la expresión auténtica argentina"6.
\end{abstract}

Los puristas resentían el énfasis que se le daba a la lengua hablada a la cual se asimilaban voces importadas de otros idiomas y sistemas fonológicos sobrepuestos que corrompían la integridad y funcionalidad del idioma español como lengua de cultura. Uno de ellos, Calixto Oyuela manifiesta en 1884 al respecto:

"Pueblo nuevo, necesitado de aprender mucho, y en relación fácil y frecuente con las naciones más avanzadas de Europa..., corremos el riesgo inminente de caer en uno de estos dos viciosos extremos: el criollismo vulgar y estrecho, inspirado por una especie de patriotismo municipal $ұ$ casero; o el sacrificio de todo espíritu, de todo carácter nacional en aras de una imitación servil y mal entendida de los modelos extraños"7.

La amenaza de un cambio lingüístico y cultural temida por las capas sociales más altas se manifestó en intrépidos combates intelectuales que pueden resumirse en tres posiciones fundamentales: una postura casticista y conservadora que se aferraba a un purismo normativo que veía cada cambio como un vicio que debía combatirse, con ejemplos tales como el de Miguel Cané, que en una crítica amable al Martin Fierro le reprocha a José Hernández que su "forma es incorrecta" aunque comprende que ello se deba "a la naturaleza del estilo adoptado"8; y la de Bartolomé Mitre, quien le escribe:

No extrañará que le manifieste con franqueza, que creo que usted ha abusado un poco del naturalismo, y que ha exagerado el colorido local, en los versos sin medida de que ha sembrado intencionalmente sus páginas, así como con ciertos barbarismos que no eran indispensables.

El interés que produce el lenguaje rural al evocar un espacio rústico, lejano, poblado de individuos aferrados a la tierra y a una naturaleza que sirve "como telón de fondo sentimental, comprometida o indiferente a la emoción humana; como escenario exótico, o como temible fuerza telúrica en constante acecho"10 refuerza la idealización del campo como alternativa al percibido vacío ancestral del argentino. Walter Bruno Berg lo expresa en términos de insatisfacción con el contexto político de la época:

"La recepción masiva del Martín Fierro... se concretó en una burguesía que encontró en él un modelo alternativo de su identidad, o sea, de su 'argentinidad'. Los lectores del Martín Fierro se reclutaron de entre esos sectores de burguesía cuyo descontento con la política de los gobiernos liberales -por razones muy diversas- iba creciendo" ${ }^{11}$.

Es importante a su vez destacar la cautelosa presunción pedagógica que José Hernández invoca al publicar su obra, pretendiendo haberla compuesto para beneficio de la "casi primitiva" población de las regiones rurales "que jamás habían leído"; la realidad era otra. El analfabetismo del campo no se prestaba para el mercado que se había propuesto; de hecho, el Martín Fierro fue creado y leído en la ciudad de Buenos Aires. Walter Bruno Berg explica que el libro: "no fue escrito en la Pampa, sino en un despacho de hotel con vista a la Casa Rosada, vale decir, en la misma Plaza de Mayo"12 recalcando el aspecto ficticio del discurso empleado.

La superioridad de la lengua de Cervantes era utilizada para afirmar un "nacionalismo ideológico" que implicaba, según la lingüista Mercedes I. Blanco "la lealtad hacia una norma idealizada de español peninsular"13 que se identificaba con el "alma del pueblo"14. La segunda posición era la independentista que deseaba la ruptura de la unidad lingüística hispana en su afán de establecer una lengua distinta del español; y la tercera, proponía la posibilidad de coexistencia de las diferentes variedades del español ${ }^{15}$. 
Con la oleada migratoria de los años 1857-1940 (el 44,9\% de la inmigración era de origen italiano comparado con el $33,4 \%$ de origen español) la inseguridad lingüistica se acentuó. El temor a la influencia que los inmigrantes comenzaban a tener a todo nivel social queda muy bien ilustrado por Ramos Mejía, médico y sociólogo, quien en 1899 se quejaba de que los inmigrantes lo invadian todo: los teatros, los paseos "porque son gratuitos", las iglesias "porque son creyentes devotos y mansos", las calles, los asilos, las plazas, los hospitales, los círculos y los mercados. Y lo que más le preocupaba era que de esta masa amorfa estaba emergiendo una elite ${ }^{16}$.

Los sentimientos xenófobos se nutrían de preocupaciones lingüisticas cuyo nacionalismo se expresaba con afirmaciones extremas como la de Costa Álvarez:

El hibridismo del castellano... no representa una contaminación ni una infiltración,... sino una lucha a muerte por la vida, conflicto en el cual, si el castellano se mantiene con la civilización, la barbarie caerá al fin con su lengua.

Representan esta misma lucha nuestras numerosas jergas gringocriollas, manojos e injertos en cepa gaucha de todos los dialectos italianos, y de algunas lenguas europeas, el ruso entre ellas ${ }^{17}$.

La inmigración rusa, en ese período constituía un mero $2,7 \%$. Cuando la fundación de la Asociación de Colonización Judía seleccionó en 1891 a la Argentina como lugar para el establecimiento de una colonia de emigrantes rusos, la noticia aparejó violentas acusaciones y gran alarma ya que se vislumbraba un complot que anegaría al país con 2.000 .000 de judíos ${ }^{18}$.

La desconfianza hacia lo extranjero que sentía la clase terrateniente y la elite colonial -con pretensiones aristocráticas que glorificaban la historia de sus antepasados en las guerras contra los indios, contra los españoles, contra los caudillos, etc.-, se exteriorizaba en una definición extremadamente restrictiva de quién tenía el derecho de llamarse argentino. Con la excepción de los ingleses, a quienes se consideraba de estirpe superior, todo aquel que llegaba al pais era parte de la chusma invasora de la cual no se libraba ni siquiera la clase media ${ }^{19}$. Con el sufragio secreto y universal declarado por el gobierno de Roque Sáenz Peña en 1912, todos los inmigrantes se convirtieron en ciudadanos argentinos con derecho a influir en las elec- ciones políticas ${ }^{20}$. Las elecciones sucesivas fueron ganadas por las clases medias quienes poco pudieron hacer contra las fuerzas desestabilizadoras de las clases terratenientes. Horacio Salas resume el período de transición de la siguiente manera:

En 1916 se ha producido el acceso de la clase media al gobierno, de la mano del presidente radical Hipólito Yrigoyen. La base de sustentación del poder, hasta entonces patrimonio exclusivo de la oligarquía, se ha ensanchado con los hijos y los nietos de la inmigración. La vigencia de la Ley 1420 que implantó la enseñanza laica y obligatoria aportó enormes contingentes de lectores y la temática argentina hallaba nuevos interesados. Ya no eran sólo los libros franceses los que podian nutrir las bibliotecas. La nueva clase habría de descubrir una temática casi inédita en los escritores nativos ${ }^{21}$.

En el plano lingüistico, entre los académicos que se adhirieron a la defensa de la lengua para resguardar su pureza se encontraba Américo Castro quien, con su desalmada crítica al voseo, al que se refería como "calamitoso rasgo" y sus ataques a lo que constituía la incipiente literatura nacional con declaraciones tales como "la Argentina es el único país latinoamericano que enarbola con orgullo una tradición local como la gauchesca" señalando que Don Segundo Sombra era el "arquetipo de todo los frustrados"22 provocó la ira de Borges, quien ya se había sumado al debate con su ensayo "El idioma de los argentinos", en 1927, arremetiendo contra la Academia acusándola de "coloniaje idiomático" respaldado en figuras tales como Sarmiento, Alberdi y Echeverria ${ }^{23}$, quienes buscaban separarse de la cultura hispana insistiendo en la posibilidad de una lengua propia y una literatura que reflejara la realidad argentina. Un número de la Gaceta Literaria que proclamó a Madrid como "meridiano intelectual del orbe hispánico" enfureció a Borges, quien respondió de la siguiente manera:

La sedicente nueva generación española nos invita a establecer jen Madrid! El meridiano intelectual de esta América (...) Madrid no nos entiende. Una ciudad cuyas orquestas no pueden intentar un tango sin desalmarlo; (...) una ciudad cuyo Yrigoyen es Primo de Rivera; una ciudad cuyos actores no distinguen un mexicano de un oriental; una ciudad cuya sola invención es el galicismo -a lo menos en ninguna parte hablan tanto de él- una ciudad cuyo humorismo está en el retruércano; una ciudad "envidiable" para elogiar ¿de dónde 
va a entendernos, qué va a saber de la terrible esperanza que los americano vivimos? ${ }^{24}$.

Borges, descendiente de los primeros europeos que llegaron a América, idealizó su conexión criolla a partir de las hazañas de su abuelo materno, Isidoro Suárez, quien a los veinticuatro años de edad lidió el combate de Junín, el 6 de agosto de 1824, durante la Guerra de la Independencia de España. Se avergonzaba de sus antepasados españoles a quienes juzgaba gente de poca inteligencia, soldados de una época con la cual él no se quería asociar. Entendía la Guerra de la Independencia como una rebelión de los hijos contra los padres, interpretando tal ruptura como una resolución tomada conscientemente por la población criolla de no ser más españoles, lo cual los comprometía a forjar una nueva identidad, una identidad argentina ${ }^{25}$. Inventándose un pasado y una herencia a que aferrarse, Borges se convirtió en campeón del grupo separatista ensalzando el criollismo, idealizando lo gauchesco (no al gaucho Martín Fierro, a quien calificaba de desertor, prófugo y borracho) mitificando, a su vez, al orillero y al compadrito arrabalero. El compadrito, para Borges "fue el plebeyo de las ciudades y del indefinido arrabal, como el gaucho lo fue de la llanura o de las cuchillas"26. Este lenguaje plebeyo lo prefería exento de lunfardo y, dentro de lo posible, limitado a "Los primeros tangos, los antiguos tangos dichosos [que] nunca sobrellevaron letra lunfarda: afectación que la novelera tilinguería actual hace obligatoria y que los Ilena de secreteo y de falso "énfasis"27; optando por la milonga "Alma orillera y vocabulario de todos, hubo en la vivaracha milonga; cursilería internacional y forajido hay en el tango"28. El "Hombre de la esquina rosada" incluye todo lo que en aquel entonces Borges consideraba "auténtico", el lenguaje coloquial (con algunas palabras lunfardas -muy a pesar suyo-) "quilombo", "lengue", "biaba", y un solo italianismo: "facha"29, la jerga de los compadritos, una historia y un personaje arrabalero. Según Noemí Ulla, este cuento es un texto clave para definir la identidad rioplatense de los años $30^{30}$. Borges consideraba el lunfardo como "un dialecto chúcaro y receloso -jerga aclimatada de la infamia, jerigonza carcelaria y conventillera que nos convertiría en hipócritas al revés, en hipócritas de la malvivencia y de la ruindad- es el proyecto de malhumorados y rezongones" ${ }^{\prime \prime}$.

Buscar una identidad lingüistica para Borges significaba hallar su propia identidad que, como la Argentina, se encontraba en la periferia "ese lugar ex-céntrico que es su país" al que se refiere Beatriz Sarlo ${ }^{32}$. La familia Borges se había desplazado a Suiza cuando este era un joven adolescente de quince años, a su regreso de Suiza y España tenía veintidós años y la Argentina le "pareció un territorio insípido, que ya no era, la pintoresca barbarie que todavía no era cultura..." ${ }^{33}$. Siguiendo a Beatriz Sarlo:

Borges reinventa un pasado cultural y rearma una tradición literaria argentina en operaciones que son contemporáneas a su lectura de literaturas extranjeras. Más aún: puede leer como lee las literaturas extranjeras, porque está leyendo o ha leído la literatura rioplatense ${ }^{34}$.

Esa simultaneidad cosmopolita y nacional caracteriza la tensión de la primera obra de Borges que invita a reflexionar sobre su realidad cultural y su nostálgico afán de limitar y fijar ciertos rasgos lingüísticos para satisfacer su ansia personal de pertenecer a un pasado imaginado que representara lo típico argentino. Años más tarde, en el prólogo a la biografía de Evaristo Carriego (1955), Borges confiesa su fantasía al señalar abiertamente:

Yo crei durante años, haberme criado en un suburbio de Buenos Aires, un suburbio de calles aventuradas y ocasos visibles. Lo cierto es que me crié en un jardín, detrás de una verja con lanzas, y en una biblioteca de ilimitados libros ingleses. Palermo del cuchillo y la guitarra andaba (me aseguran) por las esquinas, pero quienes poblaron mis mañanas y dieron agradable horror a mis noches fueron el bucanero ciego de Stevenson, agonizando bajo las patas de los caballos, y el traidor que abandonó a su amigo en la luna y el viajero del tiempo, que trajo del porvenir una flor marchita, y el genio encarcelado durante siglos en el cántaro salomónico y el profeta velado de Jorasán, que detrás de las piedras y de la seda ocultaba la lepra ${ }^{35}$.

La incorporación de términos y giros nuevos provenientes de otros idiomas -tanto a nivel culto como popular- se hacian parte de la lengua en forma paralela al reconocimiento que Borges hacía del lenguaje gauchesco; al desarrollo estilístico imprescindible para el esclarecimiento de premisas filosóficas y referencias culturales universales; a su emotiva oposición a la realidad del lunfardo acogida en el lenguaje coloquial y en las letras de "esa guarangada de tango" 36 . 
Sabido es que los registros lingüísticos de una lengua dependen del contexto de la obra y si es la oralidad la que se va a acentuar, deberá expresarse de acuerdo a la realidad socio-cultural de la cual proviene el personaje. En cuanto a la oralidad del lenguaje, Borges ya indica, en El idioma de los argentinos, con cierto sarcasmo, que:

\begin{abstract}
"Mejor lo hicieron nuestros mayores. El tono de su escritura fue el de su voz; su boca no fue contradicción de su mano. Fueron argentinos con dignidad: su decirse criollo no fue una arrogancia orillera ni un mal humor. Escribieron el dialecto usual de sus dias: ni recaer en españoles ni degenerar en los malevos fue su apetencia. Pienso en Esteban Echeverría, en Domingo Faustino Sarmiento, en Vicente Fidel López, en Lucio V. Mansilla, en Eduardo Wilde. Dijeron bien en argentino: cosa en desuso. No precisaron disfrazarse de otros ni dragonear de recién venidos para escribir. Hoy, esa naturalidad se gastó. Dos deliberaciones opuestas, la seudo plebeya y la seudo hispánica, dirigen las escrituras de ahora" ${ }^{37}$.
\end{abstract}

La oralidad, como testimonio auténtico de un pasado recreado, le sirvió a Borges para encontrar una herencia a la cual asirse. Pero es importante notar que el lenguaje vernáculo al que se refiere Borges es el porteño de rancio linaje. Según lo indica Angela Di Tullio, incorporando las ideas de Olea Franco:

Lo que más le importaba en ese momento, con todo, era afirmar la prioridad de la "heterogénea lengua vernácula de la conversación porteña" en su inspiración literaria, como lo dice en su prólogo a Luna de Enfrente. Borges está afirmando de esta manera la supremacía de lo porteño... asimismo, establece el poder cultural de su clase social contra la ralea cocolichesca de los inmigrantes. Como lo ha advertido Olea Franco, el fiarse a los recursos de la conversación porteña para asentar valores literarios significativos implica la capacidad de abandonarse a inflexiones instintivas que no pueden ser adquiridas o copiadas. Sólo los porteños de rancia prosapia ejercen naturalmente esta norma, que excluye por igual a los españoles autoritarios, a los provincianos reaccionarios, y a los italianos advenedizos. Interpretado de este modo, el programa de Borges es a la vez nacionalista, unitario y burgués $y$, como puede preverse, es también un programa ganador; tan es así que en realidad, "este programa nos ha regido hasta nuestros días" ${ }^{\prime \prime}$.
La paradoja que se establece a lo largo de la polémica lingüistica de Borges se produce, precisamente, por el énfasis que éste le diera a la oralidad y naturalidad del lenguaje que, por un lado, ya se había congelado en las páginas de la literatura gauchesca; y por el otro, esperaba que se fijara girando en torno a la figura del compadrito en el arrabal porteño dentro de los parámetros por él impuestos.

\section{Desde la perspectiva de Beatriz Sarlo:}

lo que Borges construye es un mito cultural, un horizonte utópico del pasado hispano-criollo que permitiria definir lo "argentino" en relación a una tradición que, como toda tradición, está siendo inventada...Borges no describe las operaciones de la gauchesca, sino que toma a la gauchesca para probar en ella, y en un puñado de escritores letrados del siglo XIX, la pre-existencia de una argentinidad que habria entrado en peligro. El lunfardo y el "arrabalero" están marcados por una ilegitimidad social que se argumenta como ilegitimidad estética. Son, al mismo tiempo, una exageración y una deformación: el lunfardo se define como una jerga artificiosa de marginales; el arrabalero como mímesis empobrecida de la oralidad de las orillas de Buenos Aires ${ }^{39}$.

La autoridad y popularidad de la obra de Borges influyeron en la extensa difusión y reconocimiento de ese mito lingüistico-cultural como percepción de "lo argentino".

Es importante notar que el debate lingüistico referido tuvo un desarrollo paralelo a la búsqueda de identidad nacional que derivó en posturas moralistas que atendian al valor espiritual de la lengua y a la resultante "corrupción del pensamiento y las costumbres". Entre las manifestaciones más extremas está la de Herrero Mayor, de 1932:

Para salvaguardar el decoro de una nación hay que defender y asentar primeramente sus bienes espirituales. Y el idioma, con la religión y la moral es bien inalienable de un pueblo; sin contar con que "los pueblos caen por su lengua"; es decir que toda decadencia de una lengua implica, sin remisión, la del pueblo que la pierda ${ }^{40}$.

Esta postura moralizante se enfocó en el lunfardo y toda desviación dialectal que incluía el voseo, y desembocó en la censura impuesta por La Dirección General de Comunicaciones dirigida principalmente "hacia las letras de temas musicales, en especial del tango, y hacia los textos radio- 
teatrales $y / 0$ teatrales que contenían expresiones lunfardas populares tenidas como contrarias a la moral pública"41.

Años más tarde, Soler Cañas, autor dedicado al estudio del lunfardo, presenta un análisis más objetivo y consecuentemente más moderado al declarar que:

El lunfardo, ya se sabe, no constituye un idioma, sino un vocabulario... El solo vocabulario lunfardesco, sin el soporte y las bisagras del castellano, no habilita a nadie para expresarse, salvo que lo haga muy rudimentariamente ${ }^{42}$.

Lo importante de esta aseveración es que el lunfardo comienza a ser visto como parte legitima de la lengua hablada en Buenos Aires, reconociéndolo como una expresión del registro coloquial de la misma sin quitarle su puesto a la lengua de prestigio representada por el lenguaje escrito culto. Sin embargo, tuvieron que pasar muchos años antes de que un autor se atreviera a escribir novelas en el lenguaje del pueblo inmigrante que poco a poco se integraba a la nueva realidad socio-lingüistica bonaerense.

Manuel Puig, autor argentino del género popular, sorprende al mundo lector con una primera novela La traición de Rita Hayworth (1968) que incorpora a la dinámica evolutiva del lenguaje la realidad lingüística oral del Buenos Aires de los años 30 y 40 a través de personajes cuya expresión oral reverbera en la memoria del autor. Carolina Castillo observa que "la novedad en la novela de Puig reside en esta forma narrativa que se construye a partir de la presentificación de voces que conversan 0 , dicho de otro modo, en la invención de un género que se funda en la narración de la conversación"43.

Nacido en 1932, Manuel Puig -de ascendencia catalana e italiana-, dejó su ciudad de provincia, Coronel Vallejos, a los quince años de edad para estudiar en un internado americano en Buenos Aires. En 1955 fue becado a Roma para estudiar cinematografía. De ahí viajó a París y a Londres; vivió en Estocolmo trabajando como asistente de dirección y traductor de subtítulos en Roma, París y Nueva York, hasta 1967 año en que volvió a Buenos Aires. La publicación de sus dos primeros libros ocasionaron amargas críticas dirigidas a su labor literaria e intolerantes manifestaciones encauzadas a su orientación sexual. Puig se exiló a Brasil, donde vivió de 1973-1975, y de allí volvió a Nueva York en donde residió hasta el año 1980.
De ahi en adelante dividía su estancia entre Nueva York y Río de Janeiro. En 1989 se trasladó a Cuernavaca, México, donde murió el 22 de julio de 1990. Es importante trazar la trayectoria de Puig para comprender su búsqueda de bienestar, tanto físico como espiritual, en el extranjero, donde vivió la mayor parte de su vida. De la Argentina sólo tenía recuerdos; uno de ellos, la voz de su tía y la de otras mujeres de su familia que sirvieron para reproducir el relato autobiográfico de su primera novela. Escribir era para Manuel Puig un ejercicio de terapia personal. Escribía novelas porque tenía problemas que necesitaba aclarar y comprender, y la mejor forma de hacerlo era a través de un intermediario, un personaje. $Y$ como sus problemas eran complejos necesitaba explayarse para poder hacerles frente $e^{44}$.

Puig se dedicó a la cinematografía antes de sorprender al mundo literario con un nuevo género narrativo que se ocupaba, especialmente en La traición de Rita Hayworth y Boquitas pintadas, de los hijos de esos inmigrantes tan temidos, faltos de voz, pegados a la radio que difundia la música popular con letras de tango y de boleros y que, deslumbrados por el mundo del cine crearon su propia lengua y actitud imaginando una sociedad a la que querían pertenecer. El pasado de sus padres les era ajeno e intrascendente; tan ajeno como la necesidad de ajustarse a la norma prescriptiva de la escuela pública que no se proyectaba hacia la realidad lingüistica de su vida cotidiana.

En una entrevista que Danubio Torres Fierro le hiciera a Puig con motivo de la publicación de El beso de la mujer araña, Puig explicó que:

La masa de la población argentina fue formada por la inmigración de principios de siglo, sobre todo los italianos, y esos campesinos que llegaron para cambiar de status era gente que venía a olvidar sus tradiciones, no a continuarlas. Por eso, a sus hijos no le aportaron nada culturalmente, ya que todo lo que fuera su tradición convenía olvidarlo. Eso explica que los hijos tuvieran, ante todo, que inventarse un idioma porque en la casa no aprendían el español. Alli sólo se hablaban dialectos. Este estilo de vida y este idioma que tuvieron que aprender, sobre todo en la calle, debió echar mano a modelos totalmente irreales, como el cancionero, los subtítulos del cine, la radio, el periodismo más popular, el tono truculento del tango. Esos modelos, además de irreales eran retóricos. ¡Ah!, me olvidaba: también estaba el 
lenguaje ultraretórico de los libros de lectura en la escuela primaria. Todo esto los Ilevó a un callejón sin salida. Existía, en todos ellos, el deseo de mejorar, de acceder a otro nivel, pero el ideal de fineza y elegancia sólo los conducía a la cursilería ${ }^{45}$.

Patricia B. Jessen se refiere a los inmigrantes caracterizados por Puig desde un punto de vista existencial al cual ella denomina "proceso en formación" en una imagen que explica la dificultad que los mismos tenían para integrarse a una sociedad cerrada:

La búsqueda de Puig es la búsqueda de una realidad extraviada. Los inmigrantes, al llegar a la Argentina no encontraron instituciones ya formadas con las cuales se podian asociar sino un andamiaje para infundirlas de completa realidad. Los personajes de Puig son recién llegados o son hijos de recién llegados. Son un proceso en formación. Para todos ellos la realidad está afuera; la realidad son los otros: los burgueses honrados, las familias legítimas, los que poseen fortuna y apellido, los que tienen títulos ${ }^{46}$.

La oralidad literaria de Puig se rebela, como la de Borges, contra la clase dirigente. Borges ve en su época la hegemonía cultural española como una imposición al americanismo incipiente y mira hacia atrás deteniéndose en lo heroico o pintoresco de una realidad inventada, transformándola en mito personal. Puig, en cambio, se enfrenta con una realidad evocada creando un mito colectivo ${ }^{47}$ : la dinámica del barrio que, según Sebreli, servía para:

satisfacer una ansiedad emocional subyacente que no encuentra otras vías de realización -creando la apariencia de que pasa algo cuando no pasa nada, inventando una historia; estableciendo una forma momentánea de comunicación, un deformado lazo humano al fin, entre los habitantes del barrio proletario ${ }^{48}$.

Esa nueva realidad reflejaba el presente de las nuevas comunidades en su relación comunitaria interna y su situación respecto a los prejuicios y demandas impuestas por la inflexibilidad de las normas sociales excluyentes.

Inmigrantes gallegos, italianos, judíos, adquieren voz volcando en sus páginas la esencia de sus vidas en el contexto socio-cultural en que se encuentran con su carga de prejuicios y estereotipos. Cuanto más alejado del idioma origi- nal, el lenguaje del hijo de inmigrantes más se inclina hacia dialecto local para integrarse. Un ejemplo de ello es Cobito (Jacobito), un personaje judio de padres rusos, cuya lengua materna es el Yiddish. En La traición de Rita Hayworth se expresa en un largo monólogo interior de adolescente resentido en el que se mezcla fantasía y realidad:

¡Y mañana lunes! Botánica, Matemáticas, Castellano y Geografía, cuatro unos me encajan y ma qué me importa si total voy a diciembre con las cuatro, y media en bolas se viene la de Geografía... no se acaba más el año, tres meses más de clase, y ya pronto se empezarán a bañar en Paraná: canta la chicharra en el río, me las pico de casa, me tiro a la sombra pescando en el fresco y si me quedo dormido con la caña en la mano... y sigo de apoliyo al sol, como una vez un pibe que se murió insolado... total en este bimestre ya cagué... una buena mina en pelotas me vendría bien después del baño, en vez de ir a Estudio... ${ }^{49}$.

Rechazando la omnisciencia de la voz narrativa ${ }^{50}$, Puig arma la trama con el movimiento de una cámara que se enfoca en los personajes dejándolos expresarse a su modo, con modelos ofrecidos por las radionovelas, canciones populares, actores cómicos que exageraban errores gramaticales y sintácticos del grupo proletario bonaerense (el de "Catita" de Niní Marshall, personaje de gran popularidad que propagó el interrogativo "¿lo qué?" y palabras tales como "déale", "haiga", "fulbo", "anédota", etc.), y subtítulos mal traducidos de películas de Hollywood. Puig traslada esas voces a la literatura con suma naturalidad, principalmente en La traición de Rita Hayworth, Boquitas Pintadas y El beso de la mujer araña, puliendo el lenguaje para que representara fiel y artísticamente el significado de la expresión usada. Puig señaló al respecto que "La realidad es necesario relatarla en términos de belleza... [agregando] que en muchos casos trabaja con un lenguaje enajenado y degradado, pero siempre lo transforma para realzar su significado social" 51 .

El contexto histórico de la década de los años 30, caracterizado por las maniobras políticas de los conservadores durante una época en que la depresión desequilibra las exportaciones tradicionales, perdiendo mercados para la colocación de productos primarios y reduciendo las divisas utilizadas en importar productos habituales, también se refleja en el medio representado por Puig:

ARBOR CLXXXVI 741 enero-febrero [2010] 119-127 ISSN: 0210-1963 
Esto resulta en el empobrecimiento del país. La Argentina deja de ser un pais rico y nacen mitos que tratan de encubrir esta realidad, dejando a las nuevas generaciones sin guias ni puntos de referencia. Esta es la realidad que se proyecta en La Tradición de Rita Hayworth. Puig encara este momento histórico desde el plano de la cultura, desde las voces de la realidad social, donde se advierten signos de una crisis profunda ${ }^{52}$.

Tanto Borges como Puig embebieron su literatura en lo que, ideológica o emocionalmente, satisfacía su imagen de lo que era "lo argentino" con relación a sí mismos. Borges, buscando en un pasado idealizado una expresión nueva, basada en la oralidad, que separara el español peninsular del argentino desde un punto de vista exterior a la realidad lingüística de su medio; Puig, desde el extranjero, introduciéndose en las entrañas del pueblo inmigrante, escribiendo a través de las voces del pasado. Ambos reflejaron en sus escritos el lenguaje de Buenos Aires; el campo y las orillas de Borges, la ciudad de provincia de Puig. Los dos se enfocaron en un sector determinado de la población; y su éxito, sumado a otros escritores argentinos del "boom" y del "post-boom", mayormente bonaerenses, crearon para el lector la ilusión representativa e inmediatamente identificable de lo que se considera ser la expresión argentina, relegando los diferentes registros lingüísticos locales y los aspectos dialectales y polifónicos del resto del país.

\section{NOTAS}

1 Entre ellos Beatriz Sarlo, Borges, un escritor en las orillas, Espasa CalpeAriel, Buenos Aires, 1995; Walter Bruno Berg, Oralidad y Argentinidad. Ensayos sobre la función del lenguaje hablado en la literatura argentina, Marcus Klaus (eds.), Tübingen (Narr.), 1997, pp. 28-41; y Mercedes I. Blanco, Lenguaje e identidad: actitudes lingüísticas en la Argentina 18001960, Gabinete de Estudios Lingüisticos, Departamento de Humanidades, Universidad Nacional del Sur, Bahía Blanca, 1991.

2 Wolf Oesterreicher, "Pragmática del discurso oral", en Oralidad y argentinidad - Estudios sobre la función del lenguaje hablado en la literatura argentina, Gunter Narr Verlag Tübingen, 1997; David Olson y Nancy Torrance, Cultura escrita e oralidade, Atica, São Paulo, 1996.

3 Wolf Oesterreicher, op. cit., p. 87.

4 Zulma M. Kulikowski, "Oralidad en la literatura: ecos de lo cotidiano en Manuel Puig", Actas del Congreso Brasileiro de Hispanistas, año 2, oct. 2002, p. 3.
5 En Mercedes I. Blanco, op. cit., p. 52. 6 En Mercedes Blanco, op. cit., p. 82. 7 Íbid., p. 50. Énfasis de la autora.

8 En Beatriz Sarlo, "Oralidad y lenguas extranjeras. El conflicto en la literatura argentina durante el primer tercio del siglo XX", p. 31.

9 libid., p. 31.

10 Sonia Thon, "El mito del campo argentino desde una perspectiva contemporánea", Actas del Congreso Internacional de Hispanistas, Promociones Universitarias, Barcelona, 1992, pp. 1025-1026.

11 Walter Bruno Berg, "Apuntes para una historia de la oralidad en la literatura argentina", Markus Klaus (ed.), Discursos de oralidad en la literatura rioplatense del siglo XIX al XX, Tübingen, 1999, p. 61.

12 Íbid., p. 61.

13 En Mercedes Blanco, op. cit., p. 54.

14 Íbid., p. 54. Calixto Oyuela, en 1943, "La lengua no es un ropaje exterior, que puede sacarse, ponerse y cambiarse a voluntad, sino la expresión inmediata que lleva embebida esencialmente el alma del pueblo que la posee."

15 ĺbid., pp. 135-136.
Aceptado: 20 de junio de 2009 
16 ADSIC, "Inmigración italiana en la Argentina", http://www.adsic. it/2007/11/20/inmigración-italianaen -la-argentina/, p. 3.

17 En Mercedes Blanco, op. cit., p. 78.

18 Wanda A. Velez, "South American Immigration: Argentina", http:// www.yale.edu/ynhti/curriculum/ units/1990/1/90.01.06.x.html, p. 6.

19 Nicholas Fraser y Marysa Navarro, Evita - The real life of Eva Perón, W. W. Norton \& Company, New York/ London, 1996, pp. 15-13. Énfasis del autor.

20 ADSIC, "Inmigración Italiana en la Argentina", http://www.adsic. it/2007/11/20/inmigracion-italianaen-la-argentina/, p. 1.

21 Horacio Salas, "Buenos Aires, mito y obsesión", Cuadernos Hispanoamericanos, n. ${ }^{\circ}$ 507, julio-septiembre de 1992, p. 390.

22 Angela Di Tullio, "El idioma de los Argentinos: Cultura y Discriminación", http://www.lehman.cuny.edu/ ciberletras/v06/bordelois.html, p. 1. Íbid., p. 3.

23 Natalio R. Botana, "Peripecias de una nación de inmigrantes", Revista de Occidente, Madrid, n. ${ }^{\circ} 186$, noviembre de 1996, p. 17.

24 Angela Di Tullio, op. cit., p. 1.

25 Edwin Williamson, Borges, a life, Viking Penguin, 2004, pp. 3-4.

26 Borges, J. L., El tamaño de mi esperanza, Buenos Aires, Seix Barral, 1994, p. 11.

27 Jorge L. Borges, El idioma de los argentinos, M. Gleizer, Buenos Aires, 1928, p. 169.
28 ĺbid., p. 169.

29 Noemí Ulla, Identidad rioplatense, 1930, La escritura coloquial (Borges, Arlt, Hernández, Onetti), Buenos Aires, Torres Agüero Editor, p. 126.

30 Noemí Ulla, op. cit., p. 126.

31 Jorge Luis Borges, El idioma de los argentinos, M. Gleizer, Buenos Aires, 1928, pp. 169-170.

32 Beatriz Sarlo, Borges, un escritor en las orillas, Ariel, 1995, p. 15.

33 En Antonio Fernández Ferrer, Borges de la A a la Z, Madrid, Siruela, 1991, 2. ed., p. 103.

34 Íbid., p. 17. Énfasis de la autora.

35 Jorge Luis Borges, Obras Completas, Madrid, Círculo de Lectores, 1992, vol. I, p. 125

36 ĺbid., p. 178.

37 Jorge Luis Borges, El idioma de los argentinos, op. cit., p. 29.

38 Angela Di Tullio, "El Idioma de los Argentinos: Cultura y Discriminación", http://www.lehman.cuny.edu/ciberletras/v06/bordelois.html, p. 2.

39 Beatriz Sarlo, "Oralidad y lenguas extranjeras. El conflicto en la literatura argentina durante el primer tercio del siglo XX", pp. 35-36.

40 Íbid., p. 110. Énfasis de la autora.

41 En Mercedes I. Blanco, p. 113.

42 Íbid., p. 133.

43 Carolina Castillo, "Manuel Puig y la novela de la conversación -El gesto de un narrador vanguardista", http:// www.ucm.es/info/especulo/numero28/narvang.html, p. 6. Énfasis de la autora.

44 Jorgelina Corbata, "BriefEncounter: An Interview with Manuel Puig", transla- ted and adapted by Ilan Stavans, Center for Book Culture.org, http://www. centerforbookculture.org/inteviews/ interview_puig.html, p. 5.

45 Manuel Puig, "Conversación con Manuel Puig, entrevista de Danubio Torres Fierro", Revista contratiempo, Buenos Aires, 2000, http://www.revistacontratiempo.com.ar/puig.htm, p. 1.

46 Patricia B. Jessen, La realidad en la novelística de Manuel Puig, Editorial Pliegos, Madrid, 1990, pp. 53-54.

47 Sobre este tema refiero a Jorgelina Corbata, Mito personal y mitos colectivos en las novelas de Manuel Puig, Tratados de Crítica Literaria, Orígenes, Madrid, 1988.

48 Juan José Sebreli, Buenos Aires, vida cotidiana y alienación, Ediciones Siglo Veinte, Buenos Aires, 1964, p. 174.

49 Manuel Puig, La traición de rita Hayworth, Seix Barral, Barcelona/Caracas/México, 1981, pp. 199-200.

50 Para una buena discusión sobre el papel de la voz narrativa en la obra de Puig remito a Lucille Kerr en "The Dis-Appearance of a Popular Author - Stealing Around Style with Manuel Puig's Pubis angelical", Reclaiming the Author. Figures and Fictions from Spanish America, Duke University Press, Durham and London, 1992, pp. 89-133.

51 En Myron L. Lichtblau, "Conceptos del lenguaje literario expresados por algunos novelistas hispanoamericanos contemporáneos", Centro Virtual Cervantes, p. 619.

52 Patricia B. Jessen, op. cit., pp. 22-23. 